\title{
Ação Antimicrobiana de Óleos Essenciais Contra Staphylococcus Aureus e Pseudomonas Aeruginosa
}

Mariane Ferenz (I), Ângela De Lucca Fazzione (I), Karine Angélica Dalla Costa (I), Marina Leda Ribeiros (I), Sheila Mello da Silveira (I), Alessandra Farias Millezi (I)

(I) IFC - Instituto Federal Catarinense - Campus Concórdia (Rodovia SC 283 - Km 08 - Vila Fragosos - Concórdia - Santa Catarina)

\section{Resumo}

Os óleos essenciais (OEs) são substâncias naturais, também chamados de óleos voláteis ou óleos etéreos. São definidos como produtos obtidos pelo metabolismo secundário das plantas e apresentam como características básicas seu cheiro e sabor. Devido a sua conhecida potencialidade como substância antimicrobiana, possuem várias aplicações industriais como alternativa a utilização de produtos de origem química. Com o aumento do número de bactérias resistentes aos antibióticos já existentes, existe um considerável interesse na investigação dos efeitos de antimicrobianos naturais, na preservação de alimentos, controle de infecções e utilização como agentes sanitizantes em indústrias de alimentos. O objetivo do presente trabalho foi pesquisar a capacidade antibacteriana dos OEs de plantas do gênero Cymbopogon contra as bactérias Pseudomonas aeruginosa e Staphylococcus aureus. A constatação de atividade antimicrobiana foi realizada por meio da metodologia de disco-difusão. O inóculo foi preparado a partir da cultura ativa de cada espécie bacteriana, diluída em solução salina $0,9 \%$ a uma concentração de aproximadamente 10 8UFC/mL, comparável à solução padrão de McFarland 0,5, verificada espectrofotometricamente a $625 \mathrm{~nm}$. A suspensão foi diluída a aproximadamente $107 \mathrm{UFC} / \mathrm{mL}$, em solução salina, e então foi utilizada para inocular placas de petri contendo ágar Mueller-Hinton, utilizando-se swab estéril. Discos de papel filtro estéreis de $9 \mathrm{~mm}$ de diâmetro e 250 
$\mathrm{g} / \mathrm{m}^{2}$ foram impregnados com $25 \mu \mathrm{L}$ de $\mathrm{OE}$ de diferentes concentrações e depositados sobre as placas inoculadas, incubadas (invertidas) a $36{ }^{\circ} \mathrm{C}$ por 24 horas. Disco comercial de cloranfenicol (30 $\mu \mathrm{g} / \mathrm{disco})$ foi utilizado como antibiótico de referência. $\mathrm{O}$ diâmetro do halo inibitório foi medido em milímetros considerando a medida do disco $(9 \mathrm{~mm})$. A análise foi realizada em triplicata com três repetições e o resultado apresentado como a média ( \pm desvio padrão). P.aeruginosa não foi sensível a nenhuma das concentrações dos OEs. S. aureus foi sensível a todos os OEs, sendo que a menor concentração em que houve formação de halos inibitórios foi 12,5\%, do OE Cymbopogon flexuosus. Verificou-se que as concentrações de 50\% e $25 \%$ dos três OEs testados (C. martini, C. flexuosus e C. winterianus) apresentaram halo inibitório, sendo o maior valor $(53,72 \mathrm{~mm})$ apresentado na concentração 50\% do OE C. flexuosus. Esse estudo permitiu concluir que os OEs apresentaram atividade biológica contra S. aureus, em especial o $\mathrm{OE}$ de C. flexuosus, demonstrando ser antimicrobiano potencial contra essa bactéria.

Palavras-Chave: Alimentos, Antimicrobianos naturais, Bactérias

Agência de Fomento: Conselho Nacional de Desenvolvimento Científico e Tecnológico - CNPq 